\title{
Electrochemical Determination of Tyrosine and Nitrite Using CS/CMWNTs/GCE-modified Electrode
}

\author{
Jun-li Zhang ${ }^{*}$, Rong-qiang Li \\ College of Chemical and Pharmaceutical Engineering, Huanghuai University, Zhumadian 463000, \\ China \\ *E-mail: zjlwzq529@ sina.com
}

doi: $10.20964 / 2018.04 .130$

Received: 15 December 2017 / Accepted: 9 February 2018 / Published: 6 March 2018

\begin{abstract}
A novel electrode was successfully made by modifying a glassy carbon electrode (GCE) with a chitosan (CS)/carboxylated multi-walled carbon nanotube (CMWNT) composite. The electrochemical behavior of L-tyrosine (L-Tyr) and nitrite $\left(\mathrm{NO}_{2}{ }^{-}\right)$was investigated using cyclic voltammetry, and the detection conditions of L-Tyr and $\mathrm{NO}_{2}^{-}$were explored. The effective area of the CS/CMWNTs/GCE was calculated to be $7.2534 \times 10^{-6} \mathrm{~cm}^{2}$. The surface area of the electrode membrane surface increased significantly. Accelerating the electron transfer of $\mathrm{K}_{3}\left[\mathrm{Fe}(\mathrm{CN})_{6}\right]$ is beneficial for the adsorption and enrichment of the measured substance. The results showed that the amperometric response of the sensor reached a maximum when the $\mathrm{pH}$ of phosphate-buffered saline (PBS) was 3.6 and 4.7 for L-Tyr and $\mathrm{NO}_{2}{ }^{-}$, respectively. The modified electrode could detect $\mathrm{L}-\mathrm{Tyr}$ and $\mathrm{NO}_{2}{ }^{-}$in the linear concentration ranges of $1.0 \times 10^{-8}-2.0 \mathrm{M}$ and $1.5 \times 10^{-8}-0.3 \mathrm{M}$, respectively. The detection limits were $1.6 \times 10^{-9} \mathrm{M}$ and $2.1 \times 10^{-9}$ for L-Tyr and $\mathrm{NO}_{2}^{-}$, respectively $(\mathrm{S} / \mathrm{N}=3)$. These results demonstrate the high stability and reproducibility of detection, obtained using the CS/CMWNTs/GCE. The modified electrode was applied to determine the L-Tyr content of amino acid injections and the $\mathrm{NO}_{2}^{-}$content of salted radish.
\end{abstract}

Keywords: Carboxylated multi-walled carbon nanotubes, chitosan, CS/CMWNTs/GCE, tyrosine, $\mathrm{NO}_{2}^{-}$

\section{FULL TEXT}

(C) 2018 The Authors. Published by ESG (www.electrochemsci.org). This article is an open access article distributed under the terms and conditions of the Creative Commons Attribution license (http://creativecommons.org/licenses/by/4.0/). 